This is the author's final, peer-reviewed manuscript as accepted for publication. The publisher-formatted version may be available through the publisher's web site or your institution's library.

\title{
Local heat transfer coefficient for pool boiling of $R-134 a$ and R-123 on smooth and enhanced tubes
}

Evraam Gorgy, Steven Eckels

How to cite this manuscript

If you make reference to this version of the manuscript, use the following information:

Gorgy, E., \& Eckels, S. (2012). Local heat transfer coefficient for pool boiling of R-134a and R-123 on smooth and enhanced tubes. Retrieved from http://krex.ksu.edu

\section{Published Version Information}

Citation: Gorgy, E., \& Eckels, S. (2012). Local heat transfer coefficient for pool boiling of R-134a and R-123 on smooth and enhanced tubes. International Journal of Heat and Mass Transfer, 55(11-12), 3021-3028.

Copyright: (c) 2012 Elsevier Ltd.

Digital Object Identifier (DOI): doi:10.1016/j.ijheatmasstransfer.2012.02.012

Publisher's Link: http://www.sciencedirect.com/science/article/pii/S0017931012000750

This item was retrieved from the K-State Research Exchange (K-REx), the institutional repository of Kansas State University. K-REx is available at http://krex.ksu.edu 


\title{
Local Heat Transfer Coefficient for Pool Boiling of R-134a and R-123 on Smooth and Enhanced Tubes
}

$\begin{array}{llllll}\begin{array}{l}\text { Nomenclature } \\ A\end{array} & \text { Area } & L & \text { Length } & \rho & \text { Density } \\ C & \text { Constant } & \dot{m} & \text { Mass flow rate } & R_{p} & \text { Glattungstiefe (roughness factor) } \\ C_{p} & \text { Specific heat at constant pressure } & M & \text { Molecular weight } & R_{\text {wall }}^{\prime} & \text { Wall thermal resistance } \times A_{c} \\ C_{q} & \text { Empirical constant } & n_{s} & \text { Nucleation site density } & T & \text { Temperature } \\ D & \text { Diameter } & P_{r} & \text { Refrigerant reduced pressure } & T_{\text {sat }} & \text { Saturation temperature } \\ h_{w} & \text { Water heat transfer coefficient } & P & \text { Water pressure } & \Delta T_{1} & T_{\text {water }, \text { in }}-T_{\text {sat }} \\ h_{r} & \text { Refrigerant heat transfer coefficient } & q^{\prime \prime} & \text { Heat flux } & U & \text { Overall heat transfer coefficient } \\ k_{c} & \text { Copper thermal conductivity } & Q & \text { Total heat transfer } & v & \text { Specific volume }\end{array}$

Evraam Gorgy, Ph.D.

Wolverine Tube, Inc.

2100 Market St NE

Decatur, Alabama 35609

United States

Phone: $256-580-3771$

Fax: 256-580-3502

E-mail: evraam.gorgy@wlv.com

\author{
Steven Eckels, Ph.D. \\ Kansas State University \\ 64 Seaton Hall \\ Manhattan, Kansas 66506 \\ United States \\ Phone: 785-532-2283 \\ Fax: 785-532-6642 \\ E-mail: eckels@k-state.edu
}

\section{KEYWORDS}

Boiling Heat Transfer, Refrigerants Pool Boiling, Flooded Evaporators, Enhanced Tubes, Local Heat Transfer Coefficient, Enthalpy Based Heat Transfer Analysis

\section{ABSTRACT}

The current paper presents experimental investigation of nucleate pool boiling of R-134a and R-123 on enhanced and smooth tubes. The enhanced tubes used were TBIIHP and TBIILP for R-134a and R-123, respectively. Pool boiling data were taken for smooth and enhanced tubes in a single tube test section. Data were taken at a saturation temperature of $4.44{ }^{\circ} \mathrm{C}$. Each test tube had an outside diameter of $19.05 \mathrm{~mm}$ and a length of 1 $\mathrm{m}$. The test section was water heated with an insert in the water passage. The insert allowed measurement of local water temperatures down the length of the test tube. Utilizing this instrumentation, local heat transfer coefficients were determined at five locations along the test tube. The heat flux range was $4-135 \mathrm{~kW} / \mathrm{m}^{2}$ for the TBIIHP tube and $5-60 \mathrm{~kW} / \mathrm{m}^{2}$ for the TBIILP tube. The resulting heat transfer coefficient range was $6,270-23,268 \mathrm{~W} / \mathrm{m}^{2} .{ }^{\circ} \mathrm{C}$ and $6,748-23,338 \mathrm{~W} / \mathrm{m}^{2} .{ }^{\circ} \mathrm{C}$ for both tubes, respectively. For smooth tube testing, the heat flux ranges were 7.3-130.7 $\mathrm{kW} / \mathrm{m}^{2}$ and $7.5-60.7 \mathrm{~kW} / \mathrm{m}^{2}$ for R-134a and R-123, respectively; with resulting heat transfer coefficient ranges of 
$1,798.9-11,379 \mathrm{~kW} / \mathrm{m}^{2} .{ }^{\circ} \mathrm{C}$ and $535.4-3,181.8 \mathrm{~kW} / \mathrm{m}^{2} .{ }^{\circ} \mathrm{C}$. The study provided one of the widest heat flux ranges ever examined for these types of tubes and showed significant structure to the pool boiling curve that had not been traditionally observed. Additionally, this paper presented an investigation of enhanced tubes pool boiling models.

\section{INTRODUCTION}

This paper presents a shell-side pool boiling of R-134a and R-123 on both smooth and enhanced tubes. Understanding pool boiling is important for many applications and is an essential component in modeling flooded evaporators (especially for tubes at the lower part of the bundle). The experimental work was performed in a singletube test facility. The test section incorporated a single $1 \mathrm{~m}$ long test tube. Unlike most studies done on pool boiling of refrigerants, where the test tube is electrically heated, this research presented the pool boiling study with a waterheated tube. A Water heated test section was an important consideration since this study is part of the ASHRAEfunded project, RP-1316. For the larger project, the performance of a large 20 tube water-heated bundle will be characterized with refrigerants and tubes used in the present study.

The current study used three different tubes, two enhanced and one smooth. The enhanced tubes included both refrigerant side and water side enhancement. The two tubes (TBIIHP and TBIILP) had different refrigerant side surfaces specifically tailored for each refrigerant. For example, low-vapor-density refrigerants (like R-123) had larger bubble sizes than those for high-vapor-density refrigerants (like R-134a). The goal of this study was to determine the local refrigerant-side heat transfer coefficient on smooth and enhanced tubes; the advantage of determining local heat transfer coefficients in pool boiling helps in understanding the effect of local heat flux on the shell side performance. While this study presents complete analysis for the local heat transfer coefficient along with perdition correlations, the average heat transfer analysis and detailed facility description was presented in Gorgy and Eckels (2010).

An additional goal of this study was to apply the enthalpy based heat transfer analysis (EBHT) method introduced in Gorgy (2008) to measure local heat transfer coefficients. First, a modified Wilson plot technique (Briggs and Young 1969 and Shah 1990) was applied to determine a correlation for the enhanced water-side heat transfer performance. Next, this correlation was used to determine the local refrigerant-side performance over a wide range of heat fluxes. In the following sections, the experimental facility and data analysis are presented first, followed by the experimental results.

\section{BACKGROUND}

Determining the local heat transfer coefficient depends on measurement of the water temperature gradient. This technique has been used in previous two phase flow studies, but it is also widely used in condensation studies other than boiling. In all liquid condensation studies, the liquid temperature increases along the heat exchanger as it picks up energy from the refrigerant. The temperature slope is detected by measuring the liquid temperature at various positions of the heat exchanger. The curve fit of the temperature profile can then be used to determine local heat fluxes. This method was first introduced in liquid condensation studies, particularly in in-tube experiments. The following studies were among the first users of this method: Goodykoontz and Dorsch (1967), Abis (1969), Azer and Kaushik (1987), Mochizuki et al. (1988), Unruh and Eckels (1995), and Gayet et al. (1992). The majority of the refrigerant pool boiling studies used an electric heater for heating the test tubes. An electric heater provides a 
constant heat flux, thus creating a different boundary condition than that obtained when using water. In the case of water heating, a temperature drop across the test section can be observed; also, the heat flux varies down the length of the tube. Therefore, the current method requires determining the curve fit equation $T=f(x)$ of the water temperature.

Typically, electrically heated tubes use thermocouples for measuring tube-wall temperature. Thus, the refrigerant heat transfer coefficient can easily be calculated using Newton's law of cooling, given the refrigerant temperature is known and the axial distribution of heat flux is assumed from the heater. Thermocouples are typically attached through drilled holes in the tube wall. An excellent example of this methodology can be found in Webb and Pais (1992), who used this technique in their study on short sections (167 mm long) for testing five refrigerants on plain and enhanced tubes. Other examples of studies using electrically heated tubes are Tatara and Payver (2000), and Kim and Choi (2000). The first study investigated pool boiling of pure R-134a from a single TBIIHP tube. The second study presented nucleate pool boiling of R-11, R-123, and R-134a on structured enhanced tubes having pores with connecting gaps. Pool boiling studies that utilized water-heated test sections are Robinson and Thome (2004) and Ribatski and Thome (2006). The two studies reported average heat transfer coefficients but no local measurements were reported. The work done by Robinson and Thome (2004) involved measurement of the water temperature drop, which was used for determining the local heat transfer coefficient of bundle boiling.

Correlations available for shell side boiling on enhanced tubes are limited in comparison to those for smooth tubes. In most cases, a simple power law correlation in the form $h=C\left(q^{\prime \prime}\right)^{n}$, where the heat transfer coefficient is expressed as a function of the heat flux only, is used to fit experimental data. Webb and Pais (1992), and Robinson and Thome (2004) used a correlation of this type to fit their experimental data. The resulting constants for this equation are different for each tube-fluid combination. In addition to the previously mentioned studies, the following presented a state of the art review on current topic: Brown and Bansal (1999), Casciaro and Thome (2001), and Webb (2004).

\section{EXPERIMENTAL APPARATUS}

The test facility had four main components: single-tube test section (shell and tube heat exchanger), condenser (brazed-plate heat exchanger), two electric water heaters, and two water pumps. The water was driven by two pumps through the test section and the water circuit. The refrigerant was driven by natural circulation.

Specifically, the liquid refrigerant exited the condenser at a higher elevation than the test section's entrance pipes, while the vapor exited from the top of the test section to the condenser. Figure lbelow shows the different system components, more details are available in Gorgy and Eckels (2010). Water temperature was measured by affixing seven thin film RTDs $(2 \mathrm{~mm} \times 2 \mathrm{~mm} \times 0.8 \mathrm{~mm})$ to an insert tube, which was placed at the center of the test tube. Additionally, the insert tube was wrapped with a thick insulated copper wire (drawing located in Appendix A) known as swirls. 


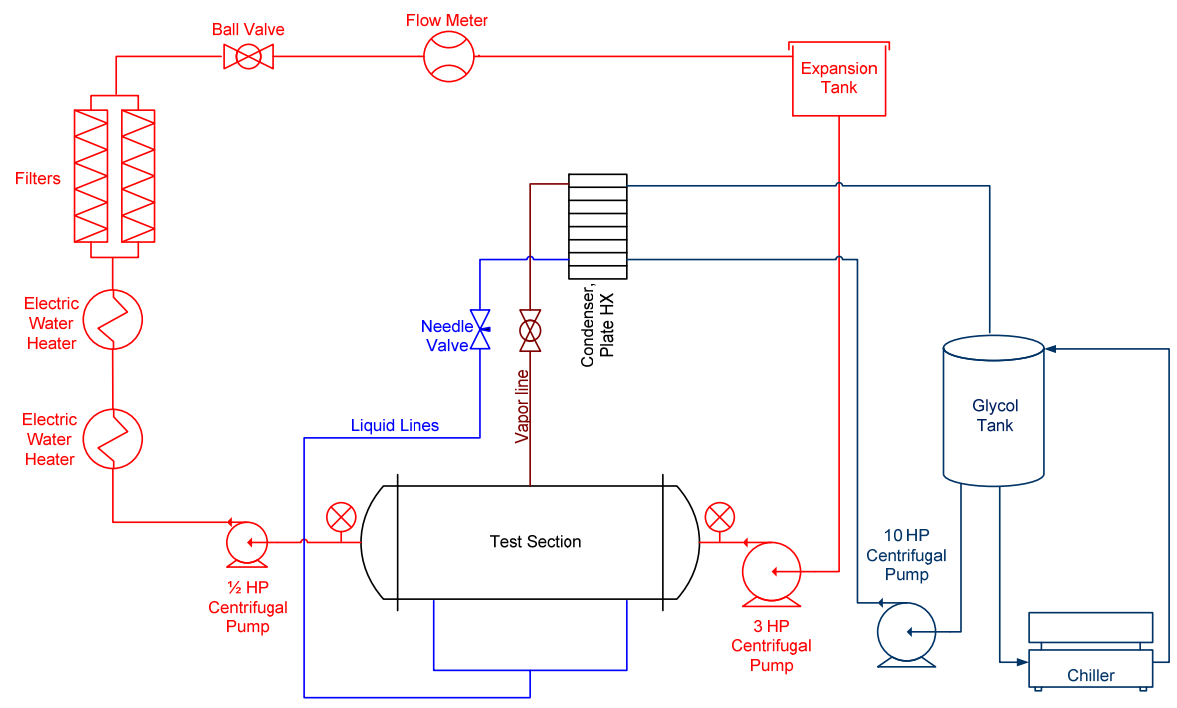

Figure 1 System Schematic

\section{Swirls function}

Prior to deciding to use the wire wrap in its current configuration (see Appendix A), data were collected using the insert tube without wrapping, with just the RTDs on the tube. Those preliminary data showed inconsistent results that often varied with heat flux and flow rate. In other words, one downstream RTD among the five RTDs may read higher than an RTD located up stream, which is physically impossible. To clear any doubts concerning functionality or calibration of the RTDs, the water flow was slowed down to the laminar regime and laminar flow heat transfer data were collected. In this case, the RTDs read a consistent temperature drop along the length of the tube. This result confirmed that both velocity and thermal boundary layers had a significant effect on the temperature measurement of the RTDs.

A theoretical prediction of the temperature profile was used as a guide for the best flow mixing pattern. Using a number of experimental trials, it was found that creating a helical passage for the water flow proved to be an effective way to minimize the velocity and thermal boundary layers' influence. Specifically, under ideal operating conditions, the predicted and measured temperatures often correlated within $\pm 0.03{ }^{\circ} \mathrm{C}$ (within temperature uncertainty), indicating the channel was functioning as intended.

It is necessary to point out that adding the helical wire wrap created only a flow pattern and did not impact the heat transfer process, i.e. it did not act as a heat addiction/withdrawal or as insulation. Only calculations of the hydraulic diameter and characteristic length were based on the water passage created by the helical channel.

\section{FINITE HEAT TRANSFER ANALYSIS}




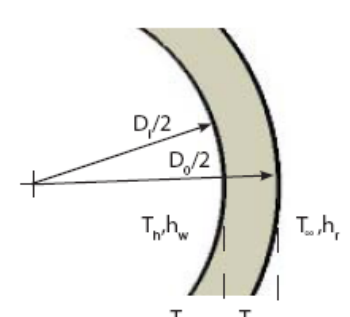

$T_{w, 1}\left|T_{\text {woo }}\right|$

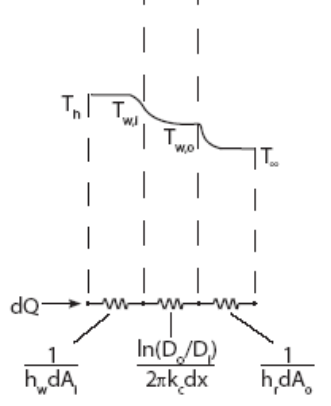

Figure 2 1-D finite control volume

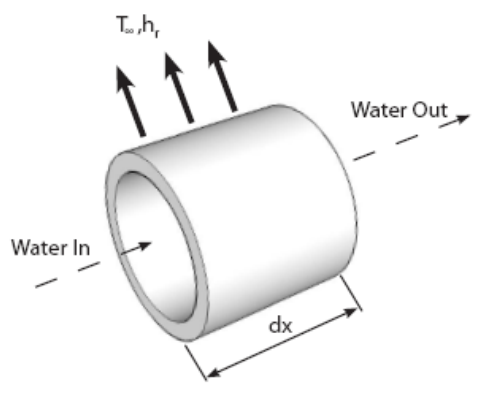

Assuming negligible axial conduction in tube wall (tube thickness $<<$ tube length), the local heat transfer coefficients can be found by applying the thermal resistances concept, as explained in Figure 2 above, which gives

rearranging yields

$$
q_{\text {local }}^{\prime \prime}=\frac{T_{\text {local }}-T_{\text {sat }}}{\frac{1}{h_{w}} \frac{D_{o}}{D_{i}}+R_{\text {wall }}^{\prime}+\frac{1}{h_{r}}}
$$

$$
h_{r}=\left(\frac{T_{\text {lcoal }}-T_{\text {sat }}}{q_{\text {local }}^{\prime \prime}}-R_{\text {wall }}^{\prime}-\frac{1}{h_{w}} \frac{D_{o}}{D_{i}}\right)^{-1}
$$

The local pool boiling coefficient was then found from the local temperature difference, local heat flux, and water side heat transfer coefficient. The water heat transfer coefficient was determined using the modified Wilson plot method (more details about this method are available in Gorgy and Eckels 2010). To determine $q_{\text {local }}^{\prime \prime}$, energy balance on the test section (or on one side of the heat exchanger) must be applied. Heat was transferred by convection through the water, then conduction through the cylindrical wall, and finally by convection through the refrigerant. This situation can be modeled as a 1-D heat transfer problem, given the assumption that heat is carried only in the radial direction.

The energy balance equation is shown in Equation 3, where the total heat added is expressed in terms of the change in enthalpy. Since the pressure drop across the tube side was significant (due to the presence of the swirls and enhancement), the conversion from this mechanical energy to thermal gain had to be taken into account.

$$
Q=\dot{m}(C_{p} \underbrace{\left(T_{\text {in }}-T_{\text {out }}\right)}_{\Delta T}+v \underbrace{\left(P_{\text {in }}-P_{\text {out }}\right)}_{\Delta P})
$$


A differential form of the above equation,

$$
\frac{d Q}{d x}=-\dot{m}\left(C_{p} \frac{d T}{d x}+v \frac{d P}{d x}\right)
$$

dividing both sides by $\left(\pi \cdot D_{o}\right)$ gives

$$
\underbrace{\frac{d Q}{\pi \cdot D_{o} \cdot d x}}_{d A}=-\frac{\dot{m}}{\pi \cdot D_{o}}\left(C_{P} \frac{d T}{d x}+v \frac{d P}{d x}\right)
$$

and assuming a linear pressure drop through the test tube yields

$$
q_{\text {local }}^{\prime \prime}=\frac{\dot{m}}{\pi \cdot D_{o}}\left(-C_{P} \frac{d T}{d x}+v \frac{\Delta P}{L}\right)
$$

In order to determine the temperature slope $d T / d x$, first a second-order polynomial (Equation 7) was used to fit the temperature measurements (seven RTDs).

$$
T=C_{1}+C_{2} \cdot x+C_{3} \cdot x^{2}
$$

Next, the temperature slope $d T / d x$ could be calculated by differentiating the above equation as

$$
\frac{d T}{d x}=C_{2}+2 C_{3} \cdot x
$$

The temperature slope could then be calculated at each of the five positions (at each heated RTD location). The water-side heat transfer coefficient required in Equation 2 was determined using the modified Wilson plot technique. The local water side heat transfer coefficient was assumed to be equal to the average water-side heat transfer coefficient, given that the change in water properties between each local position was insignificant.

\section{Local Refrigerant Heat Transfer Coefficient Uncertainty}

Table 1 Input uncertainties

\begin{tabular}{l|ll|ll|ll|l}
\hline$u_{T}$ & $\pm 0.03{ }^{\circ} \mathrm{C}$ & $u_{T_{\text {sat }, 123}}$ & $\pm 0.028{ }^{\circ} \mathrm{C}$ & $u_{C_{p}}$ & $\pm 6 \cdot 10^{-04} \mathrm{~kJ} / \mathrm{kg} \cdot{ }^{\circ} \mathrm{C}$ & $u_{P W}$ & $\pm 0.758 \mathrm{kPa}$ \\
$u_{T_{\text {sat }, 134 a}}$ & $\pm 0.02{ }^{\circ} \mathrm{C}$ & $u_{\dot{m}}$ & $\pm 0.05 \% \times$ Reading & $u_{\rho}$ & $\pm 7 \cdot 10^{-03} \mathrm{~kg} / \mathrm{m}^{3}$ & $u_{\operatorname{dim}}$ & $\pm 1.587 \mathrm{~mm}$ \\
\hline
\end{tabular}

Table 1 above shows the uncertainty of the input variables. The uncertainty of the water heat transfer coefficient was taken as the uncertainty in Gnielinski's leading coefficient determined from Wilson plot, which was presented earlier in the average heat transfer coefficient paper (Gorgy and Eckels 2010). According to Equation (9) below, two more input uncertainties was needed for determining the final uncertainty of the local refrigerant heat transfer coefficient using the propagation of the uncertainty technique. These two inputs were the uncertainty in $T_{\text {local }}$ and the uncertainty in $d T / d x$. Uncertainties were calculated for each data point and were represented by error 
bars on the results graph given in next sections. The uncertainty in $T_{\text {local }}$ was $\pm 0.03{ }^{\circ} \mathrm{C}$ as mentioned in Table 1 , this uncertainty was the combined uncertainty (propagation of error) of the calibration bath uncertainty, curve fit uncertainty, and resistance measuring uncertainty (DAQ uncertainty).

$$
h_{r}=\left(\frac{T_{\text {local }}-T_{\text {sat }}}{\frac{\dot{m}_{w}}{\pi \cdot D_{o}}\left(-C_{P} \frac{d T}{d x}+v \frac{\Delta P}{L}\right)}-R_{\text {wall }}^{\prime}-\frac{1}{h_{w}} \cdot \frac{D_{o}}{D_{i}}\right)^{-1}
$$

\section{Uncertainty in the local temperature slope}

Uncertainty in the temperature derivative (temperature slope) was difficult to determine using the propagation of error method compared to the other inputs. Therefore, a Monte Carlo type simulation was conducted to determine the temperature slope uncertainty. The overall description of this method is as follows. Using inlet and outlet temperature measurements, the average heat transfer coefficient can be predicted; using the inlet temperature and the predicted heat transfer coefficient, the temperature drop curve $T_{\text {theor }}(x)$ is determined. The temperature measurement uncertainty is added to each $T_{\text {theor }}(x)$ location according to a normal distribution of the uncertainty. A second order polynomial is then added to the "error imposed" points. The final uncertainty is then the percentage difference between the actual slope and the slope of the curve fit generated from the error imposed points.

Recalling that the insert tube measured seven temperature locations, each test point returned a temperature matrix (one by seven), and a curve fit was generated from Equation 7. Substituting the inlet temperature and the overall heat transfer coefficient in Equation 10 below, five theoretical values of the five internal local positions were determined (even though those local temperatures were already measured). Consequently, each test point returned a theoretical one by seven matrix.

$$
T_{\text {theor }}(x)=\frac{-\dot{m}_{w} \cdot v_{w} \cdot \Delta P_{w}}{U_{o} \cdot A_{o}}+\left(\frac{\Delta T_{1} \cdot U \cdot A+\dot{m}_{w} \cdot v_{w} \cdot \Delta P_{w}}{U_{o} \cdot A_{o}}\right) \cdot e^{-\left(\frac{U_{o} \cdot \pi \cdot D_{o}}{\dot{m}_{w} \cdot C_{p}}\right) \cdot x}+T_{\text {sat }}
$$

A normal distribution of 12,000 random number matrixes (again each matrix was one by seven) between $0.03{ }^{\circ} \mathrm{C}$ and $+0.03{ }^{\circ} \mathrm{C}$ (representing the uncertainty in the temperature measurement) on the theoretical temperature matrix was added, one of the 12,000 matrixes at a time, to the theoretical temperature matrix. $\mathrm{A} 2^{\text {nd }}$ order polynomial curve fit was used to fit all 12,000 temperature matrixes to produce 12,000 equations in the form

$$
T_{\text {model }}=C_{1}+C_{2} \cdot x+C_{3} \cdot x^{2}
$$

The slope of the $2^{\text {nd }}$ order polynomial above (the first derivative) was compared to the theoretical slope as shown in the following equations:

$$
\left.\frac{d T}{d x}\right|_{\text {theor }}=-\left(\frac{U_{o} \cdot \pi \cdot D_{o}}{\dot{m}_{w} \cdot C_{p}}\right)\left(\left(T(x)-T_{\text {sat }}\right)+\frac{\dot{m}_{w} \cdot v_{w} \cdot \Delta P_{w}}{U_{o} \cdot A_{o}}\right)
$$




$$
\begin{gathered}
\left.\frac{d T}{d x}\right|_{\text {model }}=C_{2}+2 C_{3} \cdot x \\
u_{d T d x}=\frac{\left.\frac{d T}{d x}\right|_{\text {model }}-\left.\frac{d T}{d x}\right|_{\text {theor }}}{\left.\frac{d T}{d x}\right|_{\text {theor }}}
\end{gathered}
$$

Each set of temperatures generated five local temperature slopes at positions 1 through 5 along the tube.

The 12,000 estimates of the temperature slope at position 1 were then sorted min. to max.; the $11400^{\text {th }}$ point $(95 \%$ confidence interval of the 12,000 points) was taken as the uncertainty in the temperature slope. Finally, Equation 15 below was applied to all variables used in calculating the local heat transfer coefficient.

$$
u_{h_{r}}=\sqrt{\left(\left(\left(\frac{\partial h_{r}}{\partial T_{\text {in }}}\right) \cdot u_{T_{\text {in }}}\right)^{2}+\left(\left(\frac{\partial h_{r}}{\partial T_{\text {out }}}\right) \cdot u_{T_{\text {out }}}\right)^{2}+\left(\left(\frac{\partial h_{r}}{\partial T_{\text {sat }}}\right) \cdot u_{T_{\text {sat }}}\right)^{2}+\left(\left(\frac{\partial h_{r}}{\partial A_{o}}\right) \cdot u_{\mathrm{A}_{o}}\right)^{2}+\ldots \ldots .\right)}
$$

General results showed the uncertainty varied significantly with heat flux. Uncertainties were as low as $1 \%$ at the highest heat fluxes and grew to $113 \%$ at the lowest heat flux. Since enhanced tubes had much higher heat transfer performance compared to smooth tubes, their heat transfer coefficient uncertainties were lower than that of the smooth tubes. Investigation of the terms in Equation 15 showed the dominate uncertainty term was associated with temperature measurement. Experimental results shown in the later section will include error bars determined from Equation 15.

\section{RESULTS}

Local refrigerant side, pool boiling heat transfer coefficients were determined for R-134a and R-123 on both smooth and enhanced tubes. Table 2 shows the range of heat fluxes and Reynolds numbers used in the experiments. The goal was to obtain an accurate, well-documented curve of the pool boiling heat transfer coefficients versus heat flux. The EBHT method was used in analyzing both smooth and enhanced tubes data.

Table 2. Test range
R-134a Smooth Tube
R-123 Smooth Tube
R-134a TBIIHP Tube
R-123 TBIILP Tube

Heat Flux Range

$\left(\mathrm{kW} / \mathbf{m}^{2}\right)$

$7.3-130.7$

$7.5-60.7$

$2.5-157.5$

$3.1-73.2$

Reynolds Number

$(\times 1000)$

$8-62 \quad 9-52 \quad 7-38.5$

$5-31$

\section{Test tube water temperature profile}

Figures $3 \mathrm{a}$ and $3 \mathrm{~b}$ are two selected data points' temperature profiles. Each plot shows the water temperature profile at a certain heat flux and Reynolds number. Each plot contains the measurement of the seven RTDs (the inlet, outlet, and five internal local RTDs) and the predicted theoretical profile according to the EBHT. The choice of five internal RTDs was the result of a Monte Carlo design simulation. This was conducted to determine the 
minimum number of temperature measurement locations that must be used to give the least sum of squares between the assumed heat transfer coefficient and the determined heat transfer coefficient, according to the polynomial curve fit of the water temperature $T=f(x)$. The regression used that provided the best fit for the five temperature locations was a two degree polynomial. Error bars on the measured temperature points (diamond points) represent the uncertainty in temperature $\left( \pm 0.03{ }^{\circ} \mathrm{C}\right)$. It's worth noting that, in some points, the error bars crossed the predicted theoretical line (which assumes a constant heat transfer coefficient).

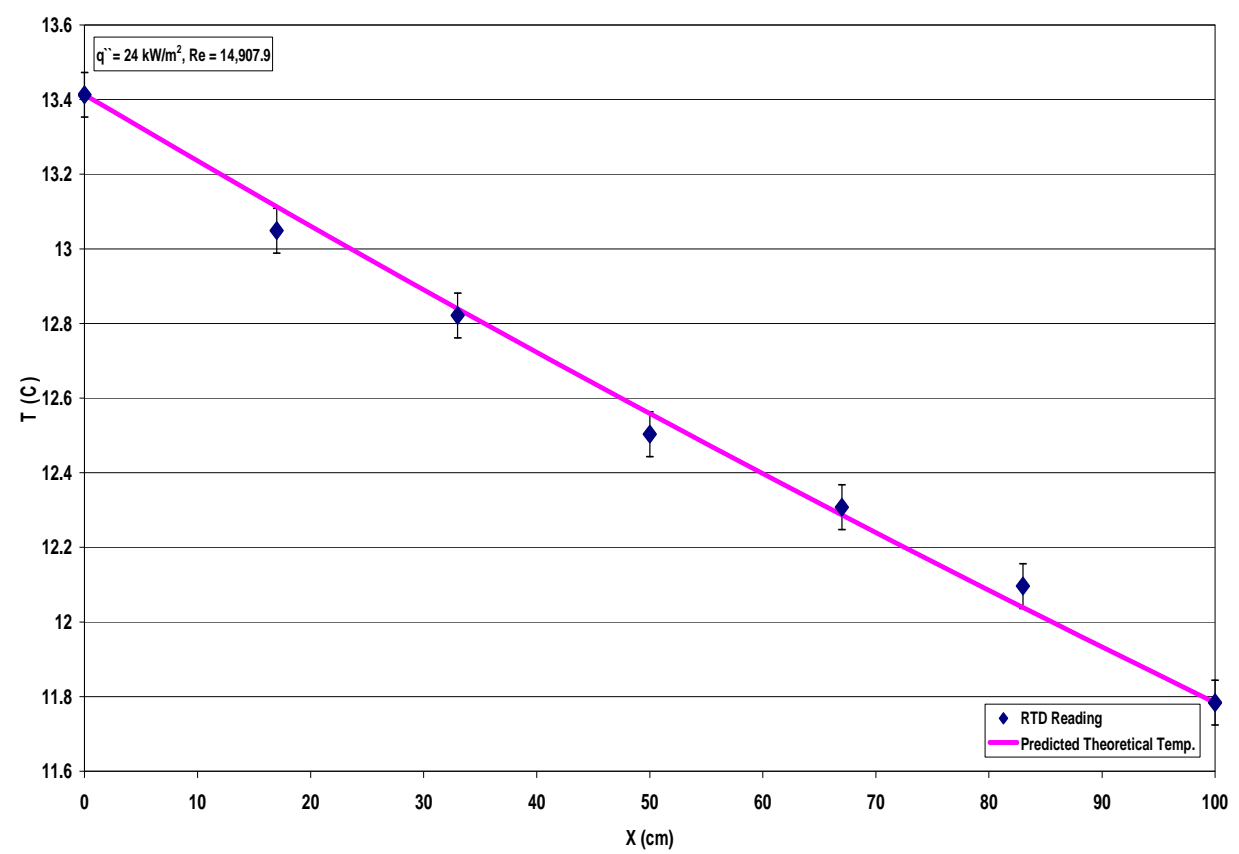

Figure 3a R-134a smooth tube temperature profile 


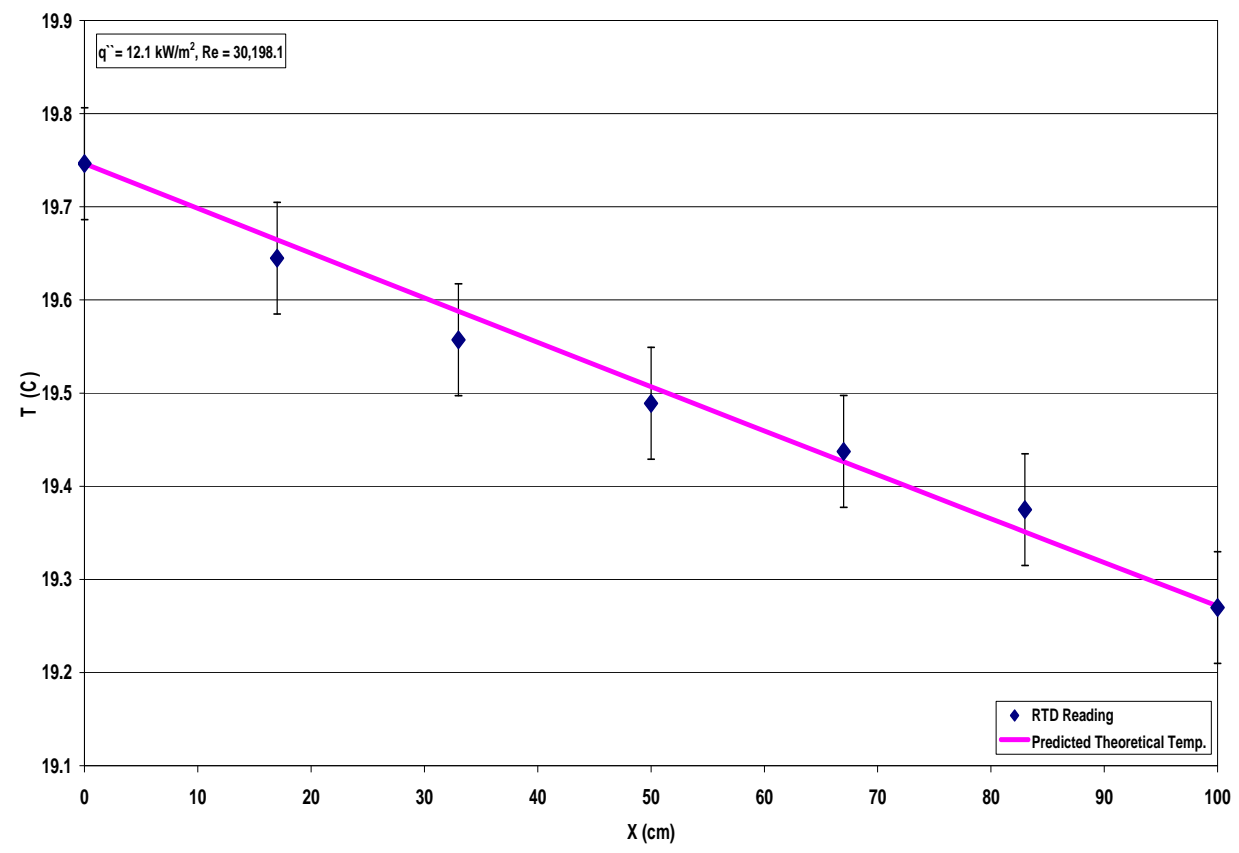

Figure 3b R-123 smooth tube temperature profile

\section{$R-134 a$ and $R-123$ smooth tube results}

Figures $4 \mathrm{a}$ and $4 \mathrm{~b}$ below show local heat transfer coefficient results of R-134a and R-123 on a smooth tube.

The change of the heat transfer coefficient for each run is represented by five local heat transfer coefficients corresponding to the five internal RTDs. The middle point always had the least uncertainty among the five points, unlike the two points on either end, which had the highest uncertainty. Almost all local heat transfer coefficient points in Figure $4 \mathrm{~b}$ showed an increasing trend with heat flux except for two runs. The first one showed a slight decrease with heat flux and the other showed no change of the heat transfer coefficient with heat flux.

Local heat transfer coefficients were compared with available experimental data in the literature. Pais and Webb (1992), and Kim and Choi (2001) evaluated the pool boiling performance of R-134a on a smooth tube using local measurements. They calculated the heat transfer coefficient based on a localized tube wall temperature measurement. Test tubes were heated using a cartridge heater. The current data was also compared with Robinson and Thome (2004), where they had used water heated test tubes (similar to the current study). Data agreed with Kim and Choi's data better than with Pais and Webb, and Robinson and Thome. 


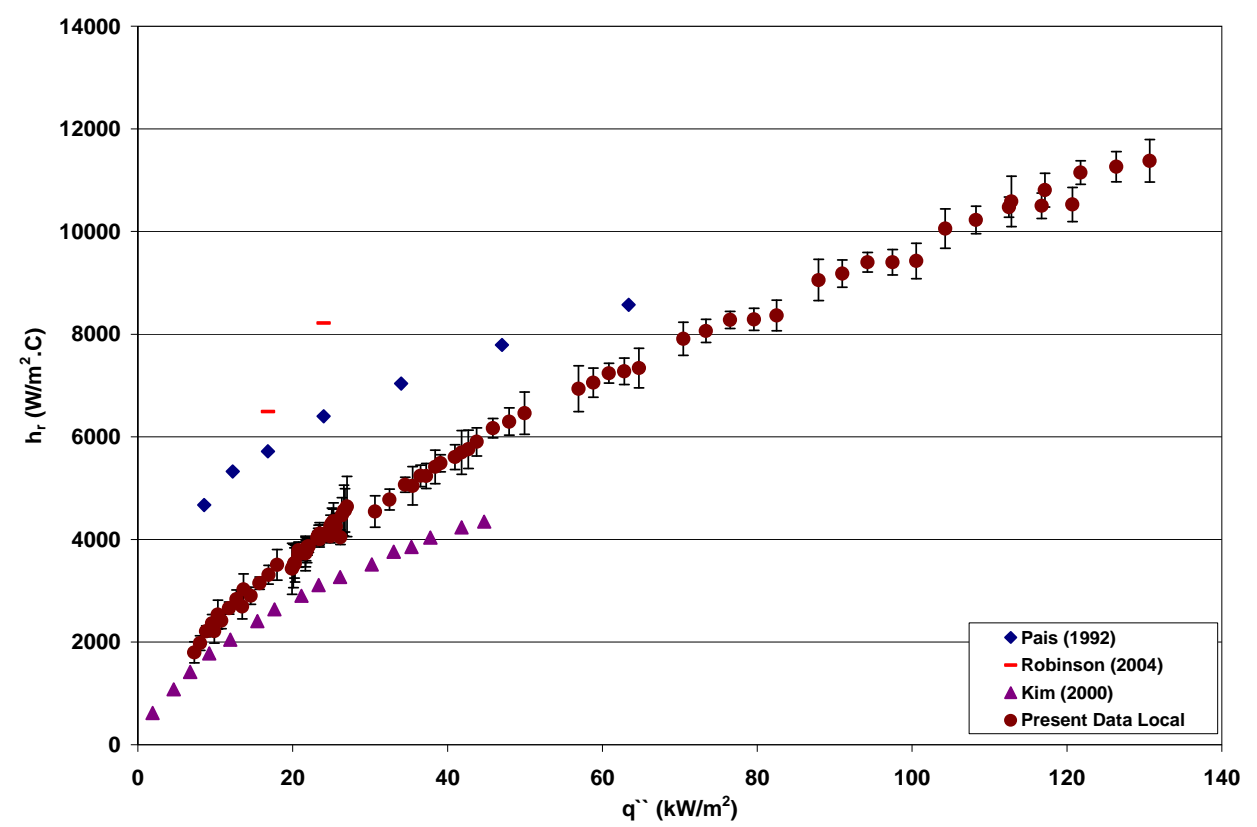

Figure 4a R-134a on smooth tube local heat transfer coefficient

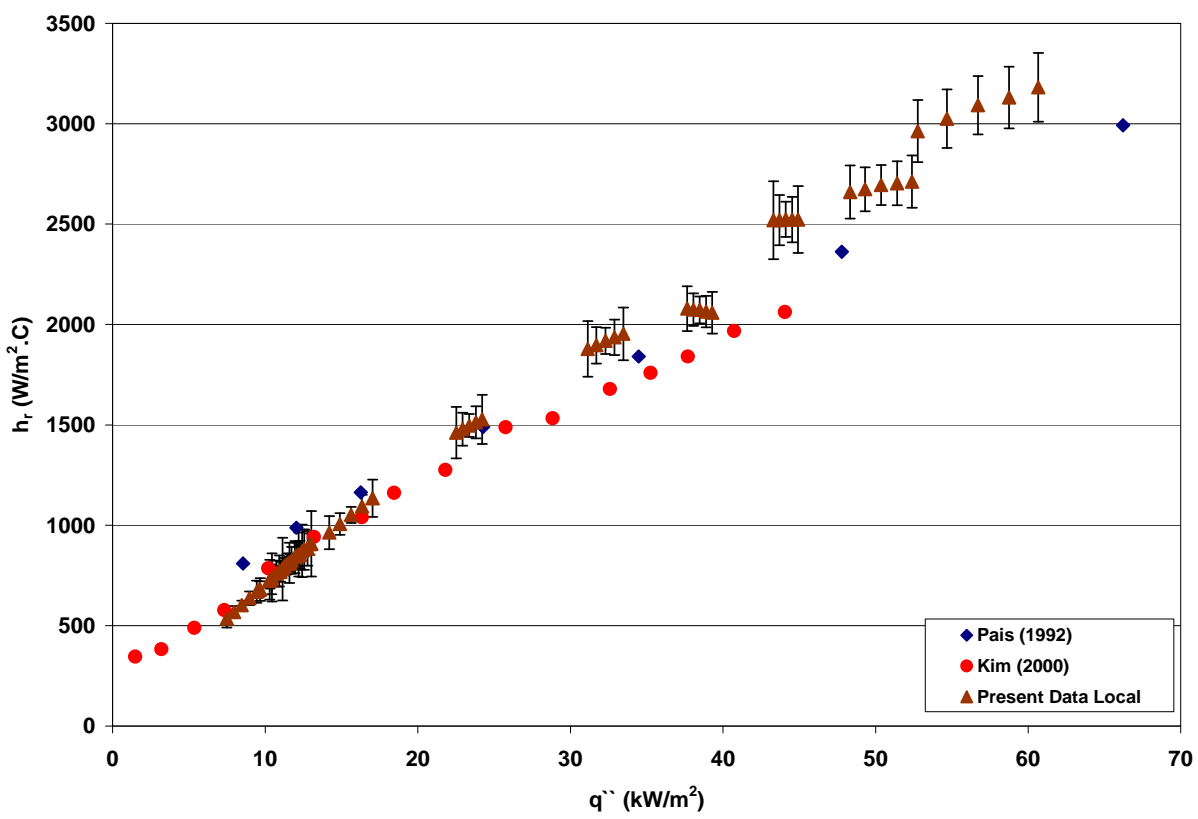

Figure 4b R-123 on smooth tube local heat transfer coefficient

\section{$R-134 a$ and $R-123$ enhanced tube results}

Figures $5 \mathrm{a}$ and $5 \mathrm{~b}$ over present the pool boiling performance of R-134a and R-123 on TBIIHP and TBIILP, respectively. R-134a on TBIIHP data were compared with Robinson and Thome (2004), Ribatski and Thome (2006), Chen and Tuzla (1996), and Tatara and Payvar (2000). Data showed a good agreement with both Robinson and Thome (2004), and Ribatski and Thome (2006). Among the available pool boiling literature, the present data (Figure 5a) showed a well-defined pool boiling behavior of R-134a on the enhanced tube TBIIHP. At 40-50 kW/m² 
heat flux, the trend showed a peak after which it started dropping then changed to a nearly constant performance. Chien and Webb (1996), parts I and II, explained this phenomenon in their study for the effect of pore diameter, pore pitch, and tunnel dimension. They concluded that at the dry-out heat flux (40-50 kW/m $\mathrm{m}^{2}$ in this case), the increasing volume of generated vapor in the tunnels caused high thermal resistance and limited the amount of liquid supply, hence decreasing the performance. Figure $5 \mathrm{~b}$ presents the pool boiling curve of R-123 on the enhanced tube TBIILP. As of now, no experimental data is available in the literature to be compared with the present study. Also, it showed the performance of both TBIIHP and TBIILP was very similar. The specific volume of R-123 was about six times that of R-134a at $4.44{ }^{\circ} \mathrm{C}$ saturation temperature. Since the same test section was used for both refrigerants at high heat fluxes, the vapor space became restricted for accommodating the increased volume of vapor. The heat flux range for testing R-123 on TBIILP was less than half of the testing range for that of R-134a on TBIIHP.

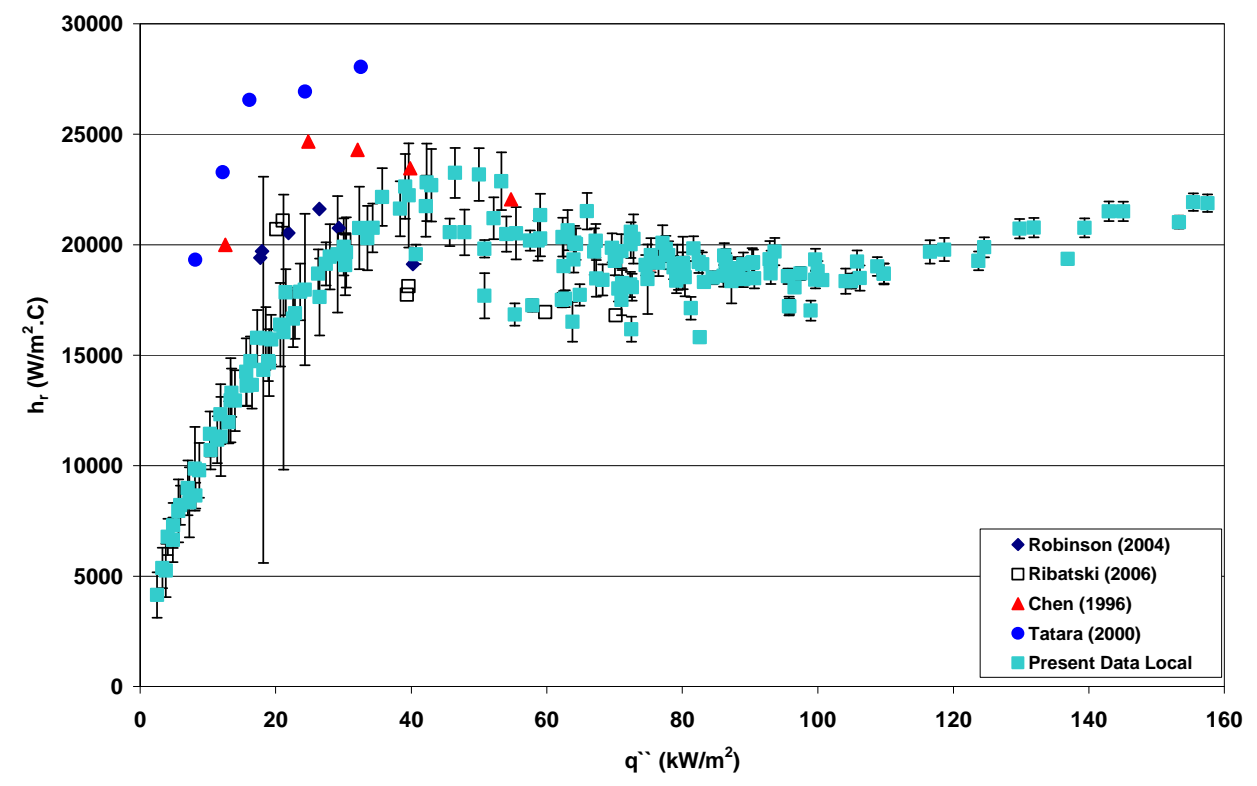

Figure 5a R-134a on TBIIHP tube local heat transfer coefficient 


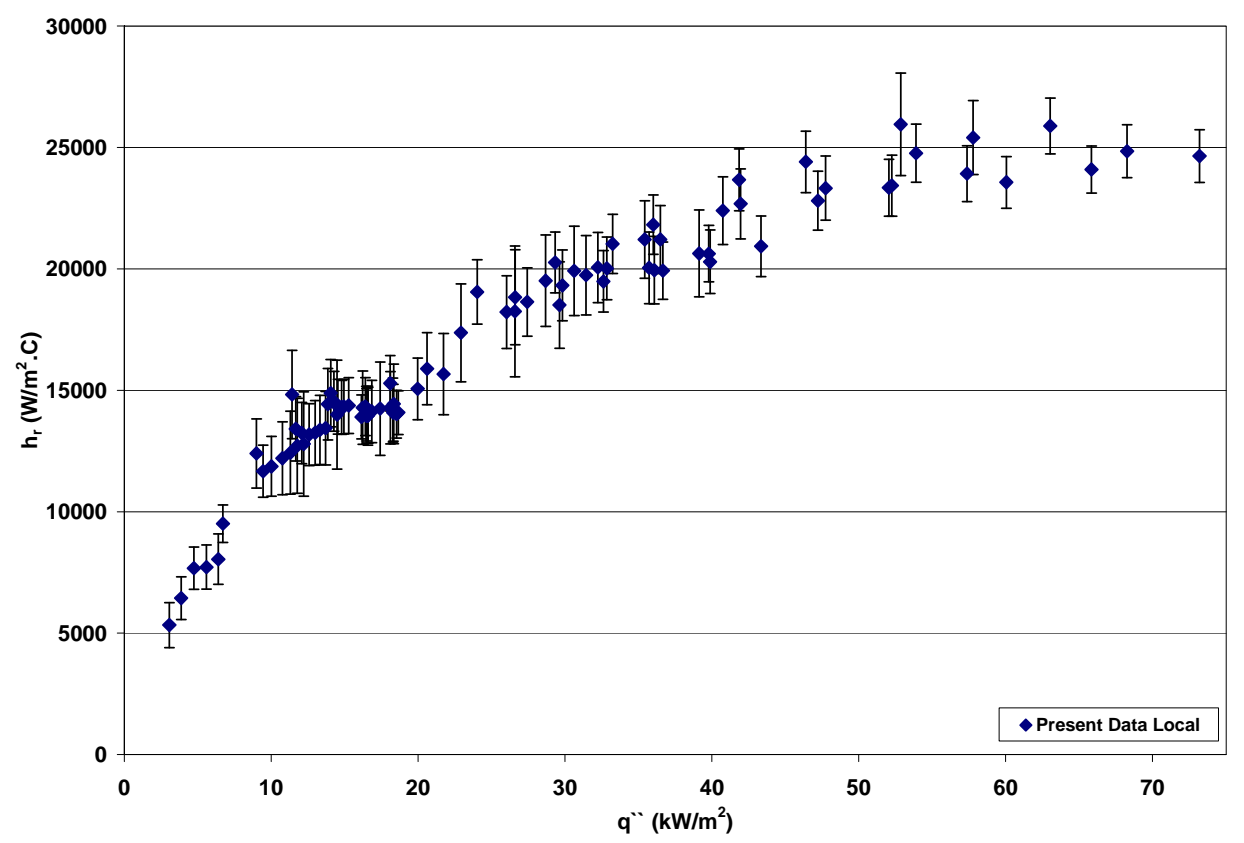

Figure 5b R-123 on TBIILP tube local heat transfer coefficient

\section{MODELING}

Developing an effective and general predictive model for the heat transfer coefficient of an enhanced tube has proven to be a difficult task. One problem encountered was the large number of experimental parameters required to completely specify the problem. For example, the surface geometry, heat flux, saturation temperature, bubble departure diameter, bubble frequency, and fluid properties all had to be known. Bubble departure and bubble frequency were the hardest to determine. Many literature review paper discussed modeling of pool boiling on enhanced tubes. Examples of key review papers are Pais and Webb (1991), Browne and Bansal (1999), Webb (2004), and Webb and Kim (2005). To the best of our knowledge, the first to introduce an analytical model for an enhanced tube were Nakayama et al. (1980). They developed a semi-analytical model of a porous surface with tunnels. They described three modes of boiling: dried up, suction evaporation, and flooded. Each mode depended on the heat flux range from high to low, respectively. Therefore, Nakayama's model was known as the "suctionevaporation" model. The model assumed that total heat flux is the summation of the tunnel heat flux and the external heat flux due to the bubble movement, as explained in Equations (16) and (17) below. But that model lacked independency on experimental data which was needed for determining seven empirical constants associated with the model. Therefore, it was a semi-analytical model.

where

$$
q^{\prime \prime}=q_{\text {tun }}^{\prime \prime}+q_{\text {ext }}^{\prime \prime}
$$

$$
q_{\text {ext }}^{\prime \prime}=\left(\frac{T_{\text {wall }}-T_{\text {sat }}}{c_{q}}\right)^{5 / 3} n_{s}^{1 / 3}
$$


Continuing with using a semi-analytical model, Chien and Webb (1998) worked an enhanced version of Nahayama's model. They used only two empirical constants compared to the seven constants of Nakayama's model. The other two models that used the same principal (suction-evaporation) were Ramaswamy et al. (2003) and Jiang et al. (2001). Murthy et al. (2006), with W. Nakayama among the authors, developed a semi-analytical model which mainly emphasized the study of the bubbles dynamic. Since all the above mentioned models used empirical constants based on experimental data, and given the different types of enhanced surfaces, it was easier to develop a model for the tubes that was completely based on experimental study. In general, researchers modeled the heat transfer coefficient for enhanced tubes after the model Cooper (1984), Equation (18) below, developed for a smooth tube.

$$
\frac{h_{r}}{\left(q^{\prime \prime}\right)^{0.67}}=55\left(P_{r}\right)^{0.12-0.2 \log _{10} R_{p}}\left(-\log _{10} P_{r}\right)^{-0.55} M^{-0.5}
$$

Since the effect of heat flux on the heat transfer coefficient on enhanced tubes differs from one tube to another and also from one refrigerant to another, the heat flux exponent constant of 0.67 was replaced by a parameter $n$. Eventually, the other parameters of Cooper's correlation were reduced to a constant for a refrigerant tested at a certain saturation temperature. Therefore, for an enhanced tube, Cooper's equation can be reduced to the form $h=C\left(q^{\prime \prime}\right)^{n}$, where the heat flux exponent and the leading constant are determined experimentally. The power law model mentioned above is widely used. It was used to predict the performance of TB tubes. The tube manufacturer listed the numerical values for the heat flux exponent and the leading constant for different refrigerants. Fortunately, the experimental investigation of nucleate boiling of enhanced tubes showed that the heat transfer coefficient is dominated mainly by heat flux. This affirms the validity of using the power law model, since its only dependent variable is heat flux.

In the current study, the heat transfer coefficient versus heat flux curves for both enhanced tubes (TBIIHP and TBIILP) had varying trends. Both curves showed an increasing trend up to the $50 \mathrm{~kW} / \mathrm{m}^{2}$ heat flux point, then the trend changed to decreasing and finally to nearly flat. Therefore, the previously mentioned power law was not quite applicable to model the whole data range. But the power law could be applied over two regions of the curve, minimum heat flux $\geq q^{\prime \prime} \geq 50 \mathrm{~kW} / \mathrm{m}^{2}(R E G I)$, and $50 \mathrm{~kW} / \mathrm{m}^{2}>q^{\prime \prime} \geq$ maximum heat flux (REGII). For the TBIIHP tube Equations (19) and (20) were applied for the low and high heat flux ranges, respectively. For the TBIILP tube Equations (21) and (22) were applied for the low and high heat flux ranges, respectively. The average of the difference between the predicted and actual values was close to zero in all four equations, with 10.3 for the highest $95 \%$ confidence interval in all cases. Notice that for the high heat flux range, the heat flux exponent was close to zero, which agrees with the nearly flat trend of both curves beyond $50 \mathrm{~kW} / \mathrm{m}^{2}$ heat flux.

$$
\begin{gathered}
h_{\text {TBIIHP }, \text { REGI }}=2970.28\left(q^{\prime \prime}\right)^{0.549} \\
h_{\text {TBIIHP }, \text { REGII }}=16354\left(q^{\prime \prime}\right)^{0.035} \\
h_{\text {TBIILP }, \text { REGI }}=3829.84\left(q^{\prime \prime}\right)^{0.455}
\end{gathered}
$$




$$
h_{\text {TBIILP,REGII }}=44353.23\left(q^{\prime \prime}\right)^{-0.162}
$$

Robinson and Thome (2004) presented a model for the TBIIHP tube with R-134a; this model was compared to the current study. Their model (presented in Equation (23) where heat flux is in $\mathrm{W} / \mathrm{m}^{2}$ ) is also a power law model based on experimental data which presented good prediction to the current experimental data as shown in Figure 6.

$$
h_{\text {TВIIHP }, 2004}=30944\left(q^{\prime \prime}\right)^{-0.042}
$$

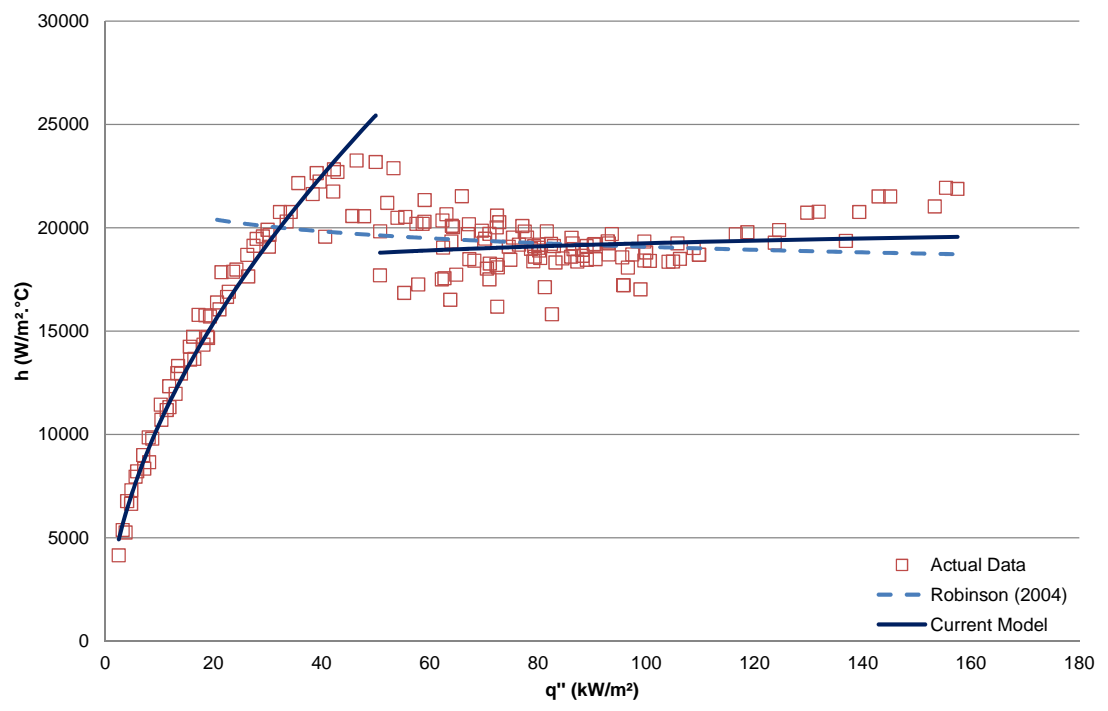

Figure 6 Model comparison

\section{CONCLUSIONS}

The current study focused on the pool boiling performance of both R-123 and R-134a on smooth and enhanced tubes. The local refrigerant side heat transfer coefficients were determined at five locations over the 1 meter long test section and were found over a wide range of heat fluxes at a saturation temperature of $4.44{ }^{\circ} \mathrm{C}$. The authors examined the effect of thermal and velocity boundary layers on the local RTDs measurement; they found that certain enhancement must be done to eliminate the boundary layer effect, thus the correct mixed cup temperature measurement. Solid, insulated wire wrapping on the insert tube was the best for serving this purpose. The actual internal water temperature (local temperatures) had a very good agreement, within the uncertainty limits, with the predicted theoretical temperature determined using the EBHT method for both high and low temperature differences. Since uncertainty in the temperature slope $d T / d x$ cannot be determined using propagation of error, the authors introduced, to the best of their knowledge, a new method for calculating this uncertainty using a Monte Carlo simulation.

Experimental results showed the enhanced tubes significantly enhanced the refrigerant side heat transfer coefficients. The present study also provided one of the widest heat flux ranges studied with this type of tubes and showed significant structure to the pool boiling curve that has not been traditionally observed. Specifically, this 
showed an initial region with a strong heat flux effect, followed by a region with very little dependence on heat flux. The current data was modeled using a power law model applied over two regions of the boiling curve.

\section{Acknowledgement}

This project was sponsored by ASHRAE as RP-1316 "Experimental Evaluation of Heat Transfer Impacts of Tube Pitch in a Highly Enhanced Surface Tube Bundle". TC 8.5 monitored the program under the chairmanship of Dr.

Petur Thors. Test tubes were donated by Wolverine Tube, Inc.

\section{References}

Abis, L. 1969. Forced convection condensation inside horizontal tubes. Ph.D. thesis, Department of Mechanical and Nuclear Engineering, Kansas State University, Manhattan, KS.

Azer, N., and N. Kaushik. 1987. Enhanced in-tube condensation by doubly augmented tubes. Final Technical Report, National Science Foundation, NSF Grand MEA-830016, Kansas State University, Manhattan, KS.

Briggs, D.E., and E.H.Young. 1969. Modified Wilson plot techniques for obtaining heat transfer correlations for shell and tube heat exchangers. Chemical Engineering Progress Symposium Series 65(92):35-45.

Browne, M., and P. Bansal. 1999. Heat transfer characteristics of boiling phenomenon in flooded refrigerant evaporators. Applied Thermal Engineering 19(6):595-624.

Casciaro, S., and J.R. Thome. 2001. Thermal performance of flooded evaporators, part 1: Review of boiling heat transfer studies. ASHRAE Transactions 107:903-918.

Chien, L.H., and R. Webb. 1998. A parametric study of nucleate boiling on structured surfaces, part I: Effect of tunnel dimensions. Journal of Heat Transfer 120:1042.

Chien, L.H., and R. Webb. 1998. A parametric study of nucleate boiling on structured surfaces, part II: Effect of pore diameter and pore pitch. Journal of Heat Transfer 120:1049.

Cooper, M.G. 1984. Saturation nucleate pool boiling, a simple correlation. First U.K. National Conference on Heat Transfer, July 3-5. Leeds, UK.

Gayet, P., Bontemps, A., and C. Marviller. 1992. Condensation of mixed vapors of R-22 and IR-114 refrigerants inside horizontal tubes. Institute of Chemical Engineeris Symposium Series 2(129):1291-1300.

Goodykoontz, J., and R. Dorsch. 1967. Local Heat Transfer Coefficients and Static Pressures for Condensation of High-Velocity Steam Within a Tube. NASA Technical Note D-3953, National Aeronautics and Space Administration, Washington, D.C.

Gorgy, E.I. 2008. Pool boiling of R-134a and R-123 on smooth and enhanced Tubes. Master's thesis, Department of Mechanical and Nuclear Engineering, Kansas State University, Manhattan, KS.

Gorgy, E.I., and S. Eckels. Average heat transfer coefficient for pool boiling of R-134a and R-123 on smooth and enhanced tubes (RP-1316). HVAC\&R 16(5): 657-676.

Gnielinski, V. 1976. New equations for heat and mass transfer in turbulent pipe and channel flow. Int Chem Eng 16:359-367.

Jiang, Y.Y., Wang W.C., Wang D., and B.X. Wang. 2001. Boiling heat transfer on machined porous surfaces with structural optimization. International Journal of Heat and Mass Transfer 44:443-456.

Kedzierski, M.A. 1995. Calorimetric and visual measurements of R-123 pool boiling on four enhanced surfaces. Report NISTIR 5732, U.S. Department of Commerce, Washington, D.C.

Kim, N. H., and K.K. Choi. 2001. Nucleate pool boiling on structured enhanced tubes having pores with connecting gaps. International Journal of Heat and Mass Transfer 44(1):17-28.

Mochizuki, S., Inoue, T., and M. Tominaga. 1988. Condensation Heat Transfer of Nonazeotropic Binary Mixtures (R-113 + R-11) in a horizontal tube. Transactions, JSME 54(503B), 1796-1801.

Murthy, S., Joshi, Y., Gurrum, S., and W. Nakayama. 2006. Enhanced boiling heat transfer simulation from structured surfaces: semi-analytical model. International Journal of Heat and Mass Transfer 49:1885-1895.

Nakayama, W., et al. 1980. Dynamic model of enhanced boiling heat transfer on porous Surfaces-Part II: Analytical modeling. Journal of Heat Transfer 102:451.

Pais, C. and R.L. Webb. 1991. Literature survey of pool boiling on enhanced surfaces. ASHRAE Transactions 97(1):79-89.

Petukhov, B.S. 1970. Heat transfer and friction in turbulent pipe flow with variable physical properties. Adv. Heat Transfer 6:503-565.

Ramaswamy, C., Joshi, Y., Nakayama, W., and W.B. Johnson. 2003. Semi-analytical model for boiling from enhanced structure. International Journal of Heat and Mass Transfer. 46:4257-4269. 
Ribatski G., and J.R. Thome. 2006. Nucleate boiling heat transfer of R134a on enhanced tubes. Applied Thermal Engineering 26(10):1018-31.

Robinson, D.M., and J.R. Thome. 2004. Local bundle boiling heat transfer coefficients on a turbo-BII HP tube bundle (RP-1089). HVAC and R Research 10(4):441-457.

Shah, R.K. 1990. Assessment of modified Wilson plot techniques for obtaining heat exchanger design data. Heat Transfer, Proceedings of the International Heat Transfer Conference 5:51-56.

Stephan, K., and M. Abdelsalam. 1980. Heat transfer correlations for natural convection boiling. International Journal of Heat and Mass Transfer 23(1):73-87.

Tatara, R.A., and P. Payvar. 2000. Pool boiling of pure R134a from a single Turbo-BII-HP tube. International Journal of Heat and Mass Transfer 43(12):2233-6.

Unruh B.J., and S.J. Eckels. 1995. In-tube condensation of R-22 and R-32/R-125 mixtures in a horizontal, smooth tube. Final Technical Report, E.I. DuPont de Numours Company, Inc. Kansas State University, Manhattan, KS.

Webb, R.L., and C. Pais. 1992. Nucleate pool boiling data for five refrigerants on plain, integral-fin, and enhanced tube geometries. International Journal of Heat and Mass Transfer 35(8):1893-904.

Webb, R.L. 2004. Odyssey of the enhanced boiling surface. Journal of Heat Transfer 126:1051-1059.

Webb, R.L., and N-H Kim. 2005. Principles of enhanced heat transfer, $2^{\text {nd }}$ Ed. Taylor \& Francis, LLC.

Appendix A

Insert Tube Drawing

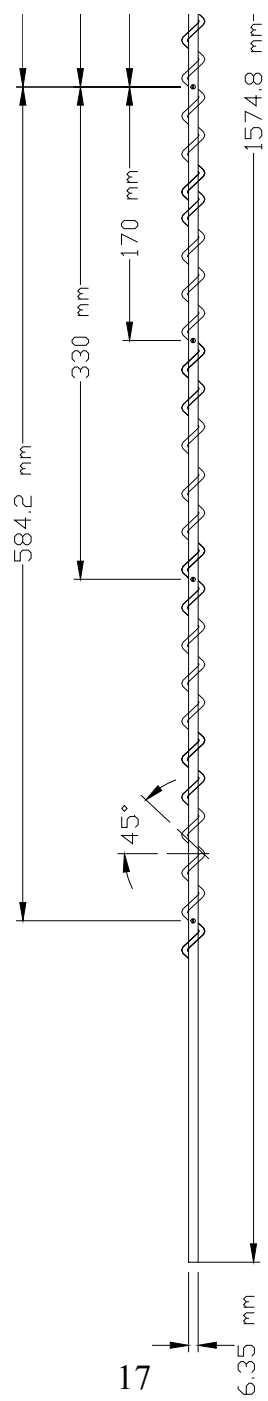

